\title{
Enhanced photodynamic destruction of a transplantable fibrosarcoma using photochemical internalisation of gelonin
}

\author{
A Dietze*,', Q Peng', PK Selbo', O Kaalhus', C Müller³, S Bown ${ }^{4}$ and K Berg' \\ 'Department of Radiation Biology, Institute for Cancer Research, The Norwegian Radium Hospital, Montebello, N-03 I O Oslo, Norway; ${ }^{2}$ Department of \\ Pathology, Institute for Cancer Research, The Norwegian Radium Hospital, Montebello, N-03 IO Oslo, Norway; ${ }^{3}$ Department of Tumour Biology, Institute \\ for Cancer Research, The Nonwegian Radium Hospital, Montebello, N-03 IO Oslo, Norway; ${ }^{4}$ National Medical Laser Centre, University College London, \\ London, UK
}

Photochemical internalisation $(\mathrm{PCl})$ is a technique for releasing biologically active macromolecules from endocytic vesicles by light activation of a photosensitiser localised in the same vesicles of targeted cells. This study investigated the PCl of the toxin gelonin as a way of enhancing the effect of photodynamic therapy (PDT) on a human malignant fibrous histiocytoma transplanted into nude mice using the photosensitiser disulphonated aluminium phthalocyanine $\left(A I P c S_{2 a}\right)$. Pharmacokinetic studies after intraperitoneal administration showed that the serum level of $\mathrm{AlPcS}_{2 \mathrm{a}}$ fitted a biexponential model (half-lives of I.8 and 26.7 h). The tumour concentration was roughly constant up to $48 \mathrm{~h}$, although fluorescence microscopy showed that the drug location was initially mainly vascular, but became intracellular by $48 \mathrm{~h}$. To compare PDT with $\mathrm{PCl}, 48 \mathrm{~h}$ after intraperitoneal injection of $10 \mathrm{mg} \mathrm{kg}^{-1} \mathrm{AlPcS}_{2 \mathrm{a}}$, and $6 \mathrm{~h}$ after direct intratumour injection of $50 \mu \mathrm{g}$ gelonin $(\mathrm{PCl})$ or a similar volume of phosphate-buffered saline (PDT controls), tumourbearing animals were exposed to red light $\left(150 \mathrm{~J} \mathrm{~cm}^{-2}\right)$. Complete response was observed for more than 100 days in $50 \%$ of the $\mathrm{PCl}$ tumours but only $10 \%$ of the PDT tumours $(P<0.01)$. In tumours examined histologically 4 days after light delivery, the depth of necrosis was 3-4 mm after PDT, but $7 \mathrm{~mm}$ after PCl. The deeper effect after PCl demonstrates that the light fluence needed to kill tumour is less than with PDT. We conclude that PCI with gelonin can markedly enhance the effect of PDT on this type of tumour and may have a role clinically as an adjunct to surgery to control localised disease.

British Journal of Cancer (2005) 92, 2004 -2009. doi:I0.1038/sj.bjc.6602600 www.bjcancer.com

Published online 10 May 2005

(c) 2005 Cancer Research UK

Keywords: photochemical internalisation; photodynamic therapy; sarcoma; pharmacokinetics; $\mathrm{AlPcS}_{2 a}$; gelonin

Photochemical internalisation (PCI) is a new technology, in which photosensitising drugs are used to improve the utilisation of macromolecules in cancer therapy in a site-specific manner (Berg et al, 1999). The concept is to localise the sensitiser and the macromolecule in endocytic vesicles of target cells and then excite the photosensitiser with light of an appropriate wavelength (photodynamic therapy, PDT). This releases the endocytically located macromolecules into the cytosol, but only in the irradiated area (PCI). The technique has the advantage of minimal side effects since the effect is localised to the irradiated area. The endosomal escape of macromolecules such as transgene substances can be increased up to a 100-fold or more (Berg et al, 1999; Selbo et al, 2000). Recently, we have demonstrated a good effect of PCI on two sarcoma cell lines in vitro (Dietze et al, 2003), although the available in vivo data is limited (Selbo et al, 2002). The aim of this study was to determine whether PCI could improve the therapeutic effect of PDT on a human soft-tissue sarcoma in a mouse model, particularly to assess whether it might have value as an adjunct to surgical excision of this type of tumour. Soft-tissue sarcomas are highly vascularised tumours with a large interstitial space and thus

*Correspondence: Dr A Dietze; E-mail: adietze@online.no

Received 18 February 2005; revised 30 March 2005; accepted 30 March 2005; published online 10 May 2005 a low density of tumour cells (Lieberman and Lebovitz, 1990). These properties may influence the pharmacokinetics of the photosensitiser as well as the transport and cellular uptake of the macromolecule of choice.

\section{MATERIALS AND METHODS}

\section{Chemicals}

Disulphonated aluminium phthalocyanine with the sulphonate groups on adjacent phthalate rings $\left(\mathrm{AlPcS}_{2 \mathrm{a}}\right)$ was provided by Frontier Scientific (Logan, UT, USA). A stock solution of $2 \mathrm{mg} \mathrm{ml}^{-1}$ in phosphate-buffered saline (PBS) was kept at $-20^{\circ} \mathrm{C}$ until use. Gelonin was purified from Gelonium multiflorum by $\mathrm{Dr}$ Gowsala Sivam, Bastyr University, Seattle, USA.

\section{Tumour model}

A human malignant fibrous histiocytoma (MFH) xenograft (TAX1), established in 1988, was provided by Professor Ola Myklebost, Department of Tumour Biology at the Norwegian Radium Hospital, Oslo. It was derived from tissue obtained during resection after local relapse. The tissue was propagated by implantation of fragments $\left(2 \mathrm{~mm}^{3}\right)$ in the left hind limb of nude 
mice (Balb/c nu/nu). These mice were maintained under specific pathogen-free conditions, with food and water supplied ad libitum. Housing and all procedures involving animals were performed according to protocols approved by the institutional animal care and use committee, in compliance with the Norwegian Animal Research Authority's guidelines on animal welfare and the guidelines of the UK Co-ordination Committee on Cancer Research (UKCCCR). To minimise the number of animals required, not all combinations of values were studied in the treatment group. Three animals per group were used for the serum and tissue analysis. The tumour size was measured by caliper in two dimensions twice a week and the volume calculated by the formula $0.5 \times\left(\right.$ length $\times$ width $\left.^{2}\right)$. Treatment commenced at a mean volume of $100 \mathrm{~mm}^{3}$ (s.d. $\pm 25 \mathrm{~mm}^{3}$ ). Animals were killed by cervical dislocation if the volume reached $1000 \mathrm{~mm}^{3}$.

\section{Extraction of the sensitiser from tumour tissue and mouse serum}

Animals injected with $10 \mathrm{mg} \mathrm{kg}^{-1} \mathrm{AlPcS}_{2 \mathrm{a}}$ i.p. were kept in the dark and $2,6,12,24,48,72,96$ and $120 \mathrm{~h}$ later, intracardiac blood samples were taken under general anaesthesia terminated by cervical dislocation. After spinning at 5000 r.p.m. for $5 \mathrm{~min}$, the serum was collected and kept frozen until analysed spectroscopically as described below to measure the drug concentration. The entire tumour harvested from the same animal was divided into two parts, one for chemical extraction of $\mathrm{AlPcS}_{2 \mathrm{a}}$ and one for fluorescence microscopy. Both parts were immediately frozen in liquid nitrogen. The tumour tissue used for chemical extraction was thawed, washed twice in PBS, weighed and then digested in $10 \mathrm{ml}, 0.1 \mathrm{M} \mathrm{NaOH}$ for $4 \mathrm{~h}$ at $50^{\circ} \mathrm{C}$. After spinning at 3000 r.p.m. for $10 \mathrm{~min}, \mathrm{AlPcS}_{2 \mathrm{a}}$ was measured spectroscopically in the supernatant at $672 \mathrm{~nm}$ (Perkin-Elmer LS-50B spectroscope with an excitation wavelength of $350 \mathrm{~nm}$ and emission detected between 550 and $750 \mathrm{~nm})$. For calibration, measurements were made on tissues extracted from animals not given $\mathrm{AlPcS}_{2 \mathrm{a}}$, but to which known concentrations of $\mathrm{AlPcS}_{2 \mathrm{a}}$ had been added.

\section{In vivo localization of $\mathrm{AlPcS}_{2 \mathrm{a}}$}

The frozen tissue blocks for localisation of $\mathrm{AlPcS}_{2 \mathrm{a}}$ were mounted in Tissue Tek II embedding compound (BDH, Poole, UK), and $8 \mu \mathrm{m}$ sections were cut with a cryostat microtome and mounted on clean glass slides. Fluorescence microscopy was undertaken using a Nikon Eclipse E800 microscope with a $100 \mathrm{~W}$ mercury lamp and fluorescence images were made with a highly light-sensitive thermo-electrically cooled charge-coupled device (CCD) camera (Hamamatsu ORCAII-ER, Japan), with a resolution of $1344 \times 1024$ pixels and a dynamic range of 16 bits per pixel. The equipment used a $330-380 \mathrm{~nm}$ excitation filter, a beam splitter and a $590 \mathrm{~nm}$ long-pass emission filter. The same lens $(\times 20)$ and integrated exposure time $(2 \mathrm{~s})$, known to cause less than $5 \%$ photobleaching of the dye fluorescence, were used throughout the study. The neighbouring tissue sections were stained with haematoxylin and eosin (H\&E) and transmission images made with a colour CCD camera (SPOT-RT, Diagnostic Instruments Inc., MI, USA) to determine the exact microscopic distribution of the dye in the tumour tissues.

For whole body images, four animals were killed $48 \mathrm{~h}$ after i.p. injection of $\mathrm{AlPcS}_{2 \mathrm{a}}\left(10 \mathrm{mg} \mathrm{kg}^{-1}\right)$ and immediately placed in the light tight chamber of an XFO-6 fluorescence option system equipped with a CCD camera (IVIS ${ }^{\mathrm{TM}}$ Imaging System 100; Xenogen Corp. Alameda, CA, USA). The peak $\operatorname{AlPcS}_{2 \mathrm{a}}$ excitation wavelength was $675 \mathrm{~nm}$ and emission was measured at $694 \mathrm{~nm}$ with a Cy 5.5 filter set, $1 \mathrm{~s}$ exposure time and a field of vision (FOV) of $25 \mathrm{~cm}^{2}$. Fluorescence emitted from the tumour tissue was used to generate a false colour image using LivingImage Software (Xenogen Corp.).

\section{Western blotting}

The abundance and stability of gelonin in the tumour tissue after intratumour (i.t.) injection was investigated by chemical extraction and Western blotting. Animals received a single i.t. injection of $50 \mu \mathrm{g}\left(25 \mathrm{mg} \mathrm{kg}^{-1}\right.$ b.w.) gelonin dissolved in PBS (pH 7.2) and were killed $10 \mathrm{~min}, 1,6,24$ or $48 \mathrm{~h}$ later. Control animals received no gelonin. At post mortem, the tumours were excised, snap frozen in liquid nitrogen and freeze-fractured with a Bio-Pulverizer (BioSpec Products, Bartlesville, OK, USA) cooled thoroughly with liquid nitrogen. Then, tissue lysate was prepared by homogenisation in a modified RIPA buffer ( $150 \mathrm{~mm}$ sodium chloride, $50 \mathrm{~mm}$ Tris- $\mathrm{HCl}$, $\mathrm{pH} 7.4,1 \mathrm{~mm}$ EDTA, $1 \mathrm{~mm}$ phenylmethylsulphonyl fluoride, $1 \%$ NP-40, $0.25 \%$ Na-deoxycholate, $1 \mathrm{~mm} \mathrm{Na} \mathrm{VO}_{4}, 1 \mathrm{~mm}$ Na-fluoride and $10 \mu \mathrm{ml}^{-1}$ protease inhibitor cocktail (Sigma, Louis, MO, USA)) for $1 \mathrm{~h}$ at $4^{\circ} \mathrm{C}$. Subsequently, tissue and cell debris were removed by centrifugation and the protein concentration of the supernatant was determined with a modified Lowry assay (BioRad, Hercules, CA, USA). The tissue lysates were boiled for $5 \mathrm{~min}$ in $1 \times$ SDS sample buffer $(50 \mathrm{~mm}$ Tris- $\mathrm{HCl} \mathrm{pH} 6.8,12.5 \%$ glycerol, $1 \%$ sodium dodecylsulphate, $0.01 \%$ bromophenol blue), separated by SDS-PAGE $\left(100 \mu \mathrm{g}\right.$ protein well $\left.^{-1}\right)$ followed by overnight transfer to a PVDF membrane (Amersham Biosciences, Buckinghamshire, England). The membrane was then blocked in a TTBS buffer containing 5\% dry-milk and afterwards probed for $1 \mathrm{~h}$ at room temperature (RT) with a rabbit polyclonal antibody (SIFF, Oslo, Norway) against gelonin. The membrane was subsequently washed $3 \times 10 \mathrm{~min}(\mathrm{RT})$ with TTBS buffer followed by probing with a HRP-linked goat-anti-rabbit antibody in TTBS buffer containing $5 \%$ dry-milk for $1 \mathrm{~h}$ at RT. To visualise the specific bands of gelonin, the ECL Plus ${ }^{\mathrm{TM}}$ (Amersham) Western blotting detection kit was used. Chemifluorescence was detected by the Storm ${ }^{\circledR}$ gel and blot imaging system (Amersham).

\section{Photodynamic therapy and PCI}

Tumour-bearing mice were allocated randomly to one of five groups: 1: PCI, 2: PDT, 3: no treatment, 4: $\mathrm{AlPcS}_{2 \mathrm{a}}+$ gelonin (no light) and 5: gelonin + light (no $\operatorname{AlPcS}_{2 \mathrm{a}}$ ). Groups 1, 2 and 4 were injected with $10 \mathrm{mg} \mathrm{kg}^{-1}$ i.p. AlPcS $2 \mathrm{a}$ and kept in the dark for $48 \mathrm{~h}$ prior to light delivery (no light in group 4). Injection of $25 \mu \mathrm{l}$ of gelonin $\left(2 \mathrm{mg} \mathrm{kg}^{-1}\right.$, groups 1,4 and 5) or PBS (groups 2 and 3) directly into the centre of the tumour was performed $6 \mathrm{~h}$ prior to delivery of red light from a $150 \mathrm{~W}$ halogen lamp (Xenophot, HLX64640) filtered through a $580 \mathrm{~nm}$ long-pass and a $700 \mathrm{~nm}$ short-pass filter $\left(150 \mathrm{~mW} \mathrm{~cm}^{-2}\right.$, total dose $\left.150 \mathrm{~J} \mathrm{~cm}^{-2}\right)$. For light delivery, the mice were fixed in a holder and the area surrounding the tumour was completely covered with aluminium foil. The mice were then kept in subdued light for a further 6 days. Tumour size was documented twice a week. If there was apparent eradication, monitoring was reduced to once a week to look for any tumour recurrence. For histological assessment, separate animals were killed 4 days after light delivery and the tumours divided at the centre of the zone of necrosis into two parts in the plane parallel to the axis of light delivery. The specimens were fixed in $4 \%$ formalin for subsequent sectioning and staining with H\&E. All histological sections were examined microscopically to document the extent of viable tumour tissue. The first cuts, representing the largest crosssection in the zone of necrosis were imaged by a scanner and hard copies printed for further estimation of the areas of viable and nonviable tumour.

\section{Analysis and statistics}

The $\mathrm{AlPcS}_{2 \mathrm{a}}$ serum concentration kinetics was analysed by nonlinear regression of $\log$ concentration $v s$ the log multiexponential decay with time. Significant differences between time points were assessed by one-way analysis of variance. Significant 
differences between PDT and PCI treatment and the histological findings after the treatment were assessed by $t$-test analysis.

\section{RESULTS}

\section{Serum and tumour pharmacokinetics}

Figure 1 shows the variation with time of the $\mathrm{AlPcS}_{2 \mathrm{a}}$ level in the mouse serum and tumour after i.p. administration. At $2 \mathrm{~h}$ after administration, the serum level was relatively high $\left(\sim 600 \mathrm{ng} \mathrm{ml}^{-1}\right)$, but this declined rapidly. The serum clearance did not follow a simple monoexponential decay, but fitted well to a biexponential two-compartment model described by the equation $C=1420 \mathrm{e}^{-0.39 t}+41.8 \mathrm{e}^{-0.026 t}$ (corr. coeff. $R=0.9916$ ). The model gives two half-lives of $1.8 \pm 0.58$ and $26.7 \pm 2.9 \mathrm{~h}$, correlating to elimination rate constants of $0.39 \pm 0.13$ and $0.026 \pm 0.003 \mathrm{~h}^{-1}$. A three-compartment model did not improve the correlation with the observations.

One-way analysis indicated that the amount of $\mathrm{AlPcS}_{2 \mathrm{a}}$ in the tumours was not significantly different between 2 and $48 \mathrm{~h}$ after administration $(P=0.62)$ and was about $400 \mathrm{ng} \mathrm{g}^{-1}$. Beyond $48 \mathrm{~h}$, $\mathrm{AlPcS}_{2 \mathrm{a}}$ was cleared from the tumour with an apparent elimination rate constant of $0.0124 \mathrm{~h}^{-1}\left(C=914 \mathrm{e}^{-0.0124 t}\right)$. This constant is based on the $\operatorname{AlPcS}_{2 a}$ concentration in the tumour ( $\mathrm{ng} \mathrm{g}^{-1}$ tissue) and is thus biased by the simultaneous growth of the tumour. The tumour doubling time in these experiments was $147 \pm 6 \mathrm{~h}$ following the regression line $V=85.5 \mathrm{e}^{0.047 t} \mathrm{~mm}^{3}$ (corr. coeff. $R=0.997$ ). The corrected elimination decay may thus be described as $A=\left[914 \mathrm{e}^{-0.0124 t}\right] \times\left[0.0855 \mathrm{e}^{0.0047 t}\right]=78 \mathrm{e}^{-0.0077 t}$, with the approximation that $1 \mathrm{~g}$ tissue equals $1 \mathrm{ml}$. The corrected elimination rate constant is $0.0077 \pm 0.0010 \mathrm{~h}^{-1}$, which indicates that the tumour growth compensates for only $0.0047 / 0.0124=38 \%$ of the tumour concentration decay.

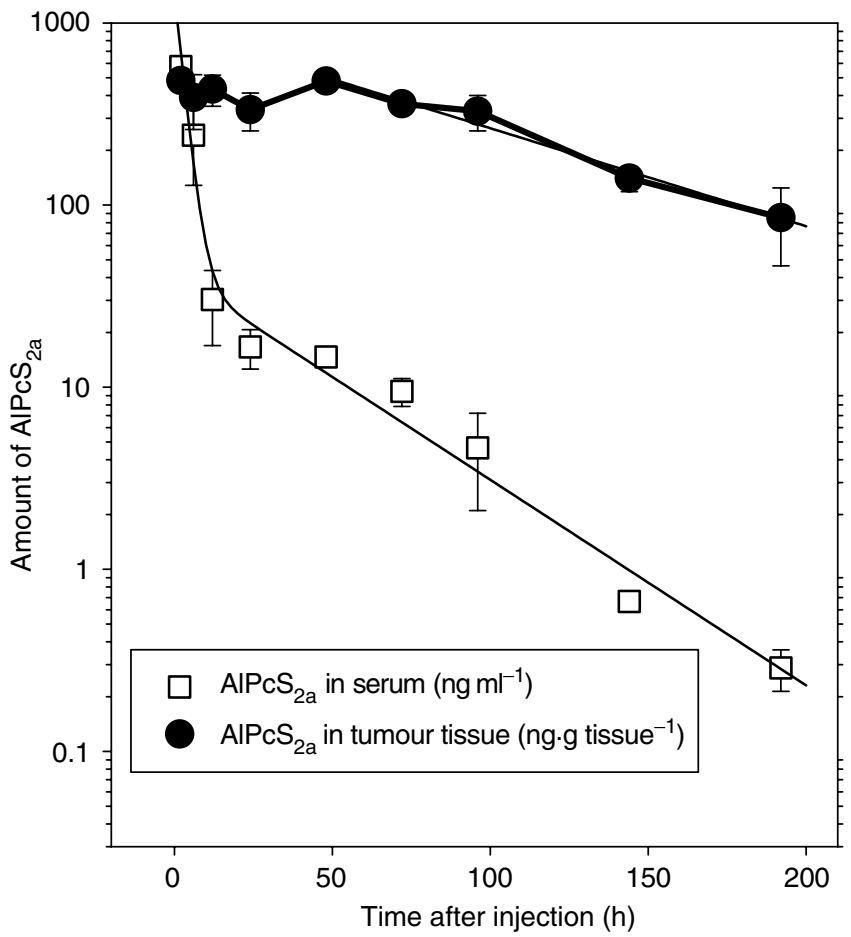

Figure I Time-dependent concentration of $\mathrm{AlPCS}_{2 a}$ in serum and tumour after i.p. injection of $10 \mathrm{mg} \mathrm{kg}^{-1}$. Regression lines are used to describe the decay of $\mathrm{AlPCS}_{2 \mathrm{a}}$ levels from $48 \mathrm{~h}$ after administration. Plots are the mean values of $3-5$ animals for each time point. Bars, s.d.

\section{In vivo localisation of $\mathrm{AlPcS}_{2 \mathrm{a}}$ in tumour-bearing mice}

A major requirement for PDT and PCI is that the photosensitiser should localise into the area to be treated. In addition, PCI requires the photosensitiser to be located in the same endocytic vesicles of parenchymal cells as the macromolecule of interest. Localisation in the blood or the tissue stroma will reduce the synergism. Our pharmacokinetic analysis indicated that $\mathrm{AlPcS}_{2 \mathrm{a}}$ was essentially eliminated from the serum within $24 \mathrm{~h}$, while the concentration in tumour tissue was stable from 2 to $48 \mathrm{~h}$ after administration. Thus, the in vivo localisation of $\mathrm{AlPcS}_{2 \mathrm{a}}$ was evaluated 2 and $48 \mathrm{~h}$ after administration by fluorescence microscopy. The cryosections obtained $2 \mathrm{~h}$ after sensitiser injection (Figure 2A) showed a fluorescence pattern indicating $\mathrm{AlPcS}_{2 \mathrm{a}}$ to be mainly in and near vascular structures as well as in the stromal compartment of the tumour, but with none in individual tumour cells. In contrast, sections obtained after $48 \mathrm{~h}$ (Figure 2B) showed a more diffuse fluorescence concentrating in the tumour cells. Although limitations in the resolution of cryosections do not allow precise determination of intracellular localisation, the nuclei seem low in $\mathrm{AlPcS}_{2 \mathrm{a}}$. Photosensitisers as used in PDT generally tend to accumulate in neoplastic lesions (Dougherty et al, 1998). To verify directly the accumulation of $\mathrm{AlPcS}_{2 \mathrm{a}}$ in tumour tissue, whole-body fluorescence imaging was used. Fluorescence emitted from tumour tissue was detected $48 \mathrm{~h}$ after photosensitiser injection (Figure $3 \mathrm{~A}$ ). Dissection of the animal verified that the low signal detected intraabdominally was from the liver (Figure $3 \mathrm{~B}$ ). The distribution pattern of $\mathrm{AlPcS}_{2 \mathrm{a}}$ fluorescence was similar after intravenous injection (data not shown).

\section{Quantification of gelonin distribution after intratumoral injection}

A prerequisite for photochemical activation of gelonin is its stable presence in the tumour cells after intratumor injection. Gelonin may be excreted by the highly vascularised sarcomas or degraded by hydrolases. Figure 4 shows that undegraded gelonin is still in the tumour $6 \mathrm{~h}$ after injection, although reduced from the amount injected. Traces of gelonin can be seen even $24 \mathrm{~h}$ after injection. It cannot be determined from these results whether the attenuation of the gelonin content in the tumour tissue is due to elimination into the blood or intratumoral degradation. No traces of degradation products were observed on the Western blots.

\section{PDT and PCI effect on tumour growth}

The time for tumours to reach $1000 \mathrm{~mm}^{3}$ (our chosen end point, at which time animals were killed by cervical dislocation) was the same ( $31 \pm 6$ days) in all control groups (no treatment, gelonin and light, $\operatorname{AlPcS}_{2 \mathrm{a}}$ with gelonin in the absence of light (Figure 5, data not shown)). Of 10 tumours treated with PDT, only one showed a complete response and four showed a growth delay of approximately 17 days. The growth curves of the others were indistinguishable from the controls. In animals treated with PCI, most tumours disappeared by 15 days after the treatment. In total, $50 \%$ of these animals (six of 12) remained tumour free although in the other $50 \%$, the tumours started to grow again by 20 days, taking $43 \pm 9$ days to reach $1000 \mathrm{~mm}^{3}$ (a delay of up to 30 days compared with the controls $(P<0.01)$ and up to 11 days compared with PDTtreated animals $(P<0.01))$. There were no significant differences in tumour volume at the time of light delivery between the complete remission group and those that regrew later. All tumour-free animals were followed for 110 days.

Histological examination of the central area of tumours 4 days after treatment showed that in the PDT group, a mean of $25 \%$ of the tumour was viable compared with $2.5 \%$ in the PCI group $(P<0.001)$ (Figure 6). Measured from the surface of the skin, the PDT effect was typically 3-4 mm deep compared with 6-7 mm 

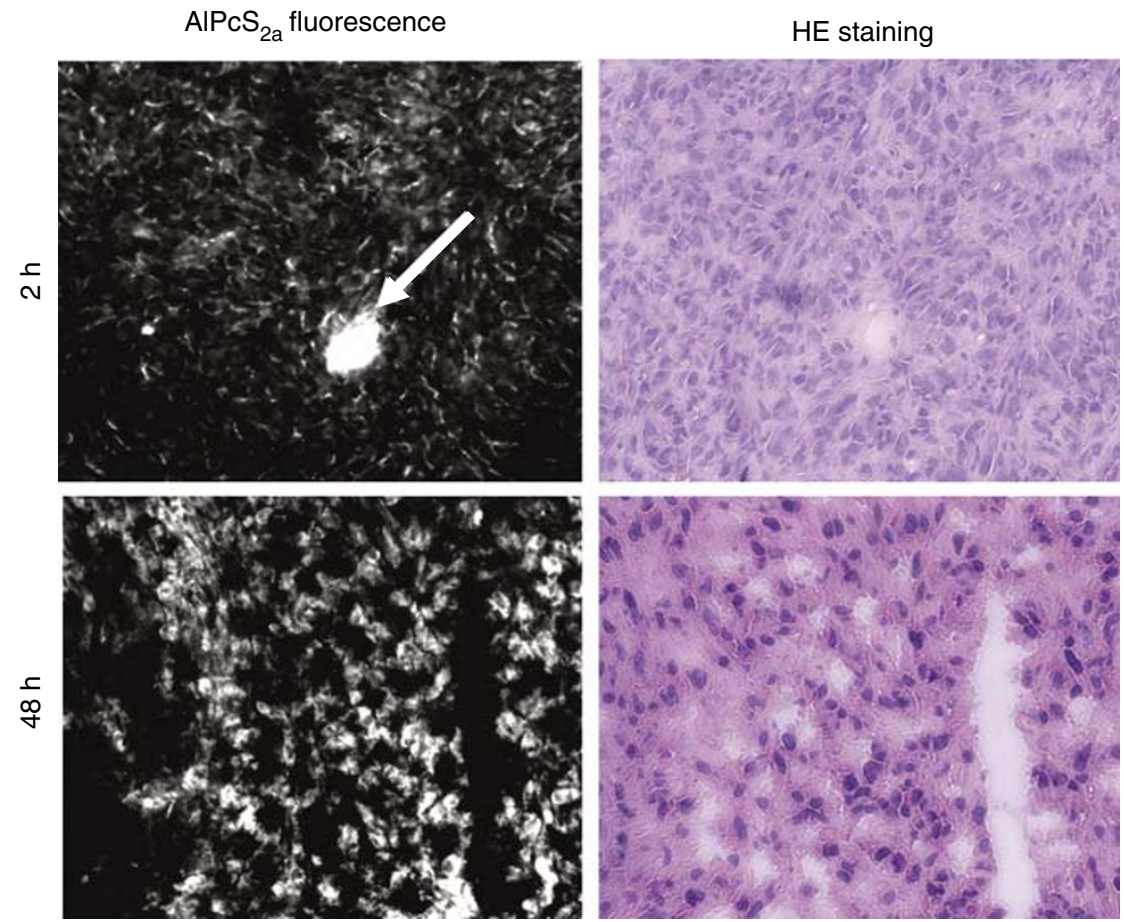

Figure 2 Distribution of $\mathrm{AlPcS}_{2 \mathrm{a}}$ in tumours after i.p. injection of $10 \mathrm{mg} \mathrm{kg}^{-1} \mathrm{AlPcS_{2a }}$. Upper photos (fluorescence and $\mathrm{H} \& \mathrm{E}$ staining): $6 \mathrm{~h}$ after injection, $\mathrm{AIPCS}_{2 \mathrm{a}}$ is mainly in the tumour vasculature. Lower photos (fluorescence and H\&E staining): $48 \mathrm{~h}$ after injection, AIPcS $\mathrm{S}_{2 \mathrm{a}}$ is mainly intracellular.
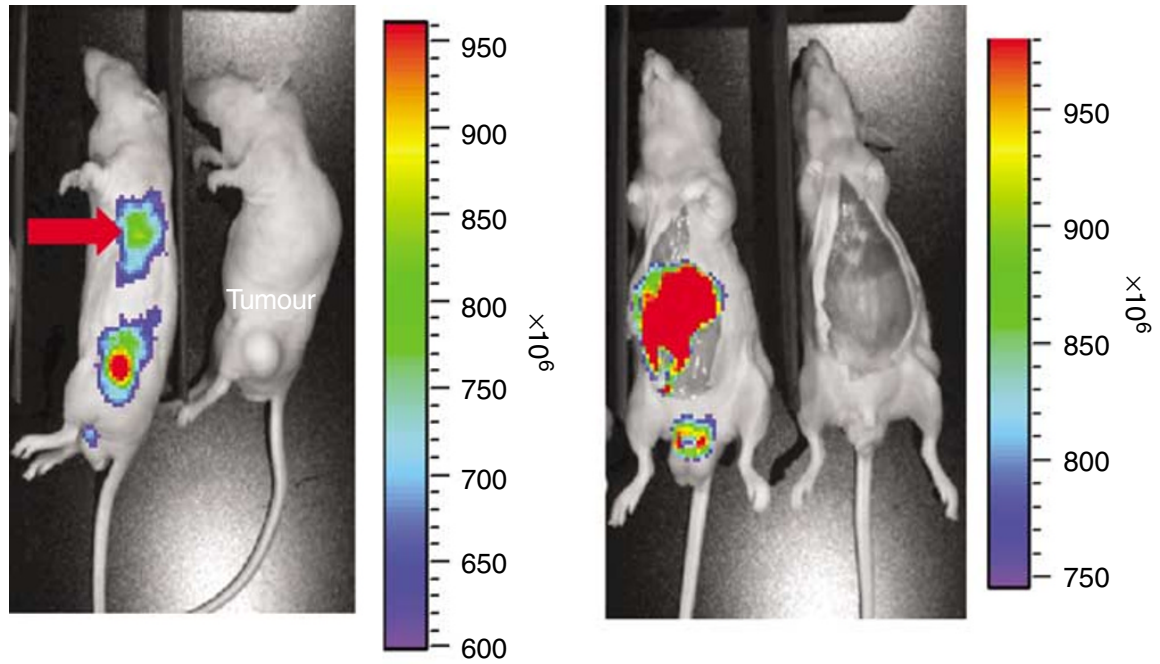

Figure 3 Macroscopic fluorescence $48 \mathrm{~h}$ after i.p. injection of $10 \mathrm{mg} \mathrm{kg}^{-1} \mathrm{AlPcS}_{2 \mathrm{a}}$. High fluorescence intensity is red and low intensity is blue. High intensity was detected in the tumour region and in the liver.

(and usually reaching the bottom of the tumour mass) for the PCI group (Figure 6). Intratumour injection of gelonin or PBS with or without light application induced a small amount of necrosis in the centre of the tumour, presumably due to a local pressure effect. However, this had no influence on the survival curve (Figure 5) or the tumour growth (data not shown).

\section{DISCUSSION}

Photodynamic therapy is a versatile treatment modality for cancer and is approved for use in the treatment of a variety of malignant and premalignant conditions (Dougherty, 2002; Dolmans et al, 2003). However, one of its main limitations is the relatively poor penetration of red light into tissue due to the absorption by natural pigments such as haemoglobin and melanin. Photodynamic therapy is therefore best suited to small and thin lesions (Dougherty et al, 1998; Moan et al, 1998). However, PCI of gelonin has been shown to reduce the fluence needed to obtain the same cytotoxic effect as with PDT (Selbo et al, 2001; Dietze et al, 2003), so increasing the depth of effect that can be achieved in solid tumours. It was therefore of particular interest to study the potential of PCI for the treatment of a solid tumour like the sarcoma studied here. The structural properties of soft-tissue 


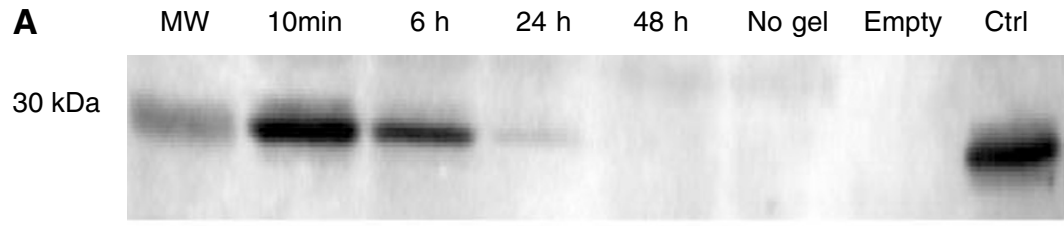

B

Figure 4 (A) Western blot showing level of gelonin in tumour at times from 10 min to $48 \mathrm{~h}$ after direct i.t. injection of $50 \mu$ g. The blot shows also an $\mathrm{MW}$ standard of $30 \mathrm{kDa}$ as well as pure native gelonin as control (ctrl) and tumour extract from untreated tissue (no Gel). (B) The PVDF membrane was stained with Ponceu $\mathrm{S}$ solution to verify even loading.

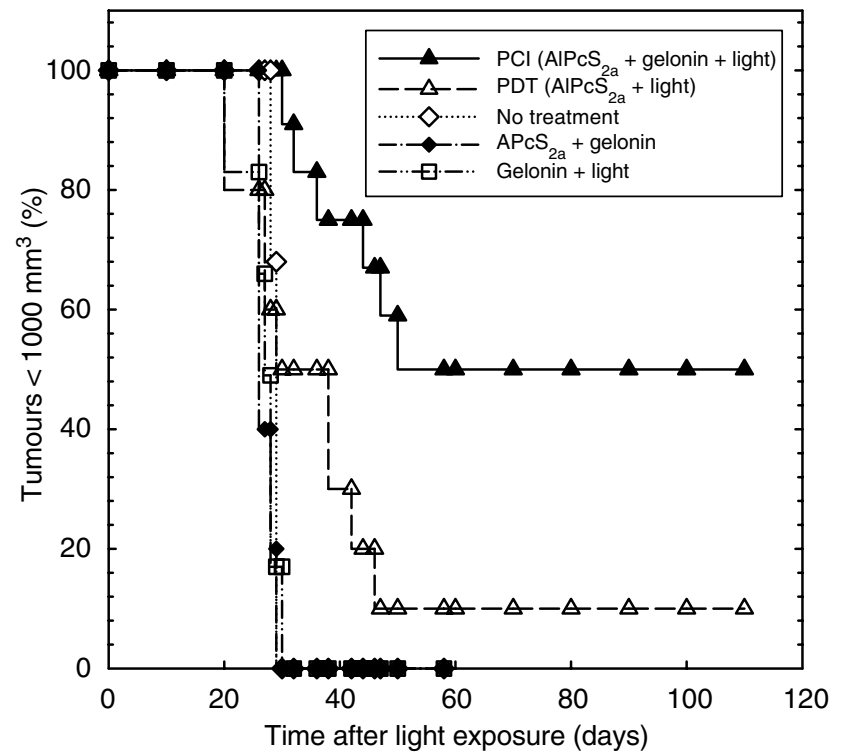

Figure 5 Tumour growth after treatment (Kaplan-Meier plot). The five groups treated were: group I: PCl, group 2: PDT, group 3: no treatment, group 4: $\mathrm{AIPCS}_{2 \mathrm{a}}$ + gelonin (no light), group 5: gelonin + light (no $\mathrm{AIPCS}_{2 \mathrm{a}}$ ). Animals were killed when the tumour volume reached $1000 \mathrm{~mm}^{3}$.

sarcomas may influence the pharmacokinetics of the photosensitiser as well as the possibility to activate the therapeutic potential of macromolecules such as gelonin photochemically.

The serum pharmacokinetics of $\mathrm{AlPcS}_{2 \mathrm{a}}$ in this study best fitted a biexponential decay. The initial rapid elimination phase, representing the distribution of the photosensitiser to the various organs was followed by a second phase representing drug elimination. The two half-lives are similar to those for the clearance of m-THPC (Cramers et al, 2003; Jones et al, 2003). At the start of the second phase (about $24 \mathrm{~h}$ after administration), the serum concentration is approximately 30 -fold lower than in tumour tissue, so from this time onwards, there is unlikely to be a significant PDT effect on blood components under the conditions required for tumour necrosis.

The tumour concentration of $\mathrm{AlPcS}_{2 \mathrm{a}}$ also showed a two-phased kinetic pattern, but with a stable concentration of about $400 \mathrm{ng} \mathrm{g}^{-1}$ tissue during the first $48 \mathrm{~h}$ after administration followed by a single exponential decay. In vitro studies indicate that photosensitisers entering cells by endocytosis tend to be retained in these vesicles for a long time $(>30 \mathrm{~h})$ as long as they are not released into the cytosol by light activation (unpublished data). The tumour clearance rate for $\mathrm{AlPcS}_{2 \mathrm{a}}$, corrected for tumour growth indicates a half-life of $90 \mathrm{~h}$ ( $56 \mathrm{~h}$ uncorrected). This stable plateau of photosensitiser concentration in tumour tissue for 1-2 days after administration followed by clearance over several days has been reported for several photosensitisers (Peng et al, 1991b). The halflife for $\mathrm{AlPcS}_{2 \mathrm{a}}$ in the tumour tissue is similar to or shorter than that of mTHPC and does not indicate that $\mathrm{AlPcS}_{2 \mathrm{a}}$ is retained in the tumour tissue for a longer time than other photosensitisers despite its expected retention in endocytic vesicles.

At $48 \mathrm{~h}$ after administration, the whole-body fluorescence images clearly showed a greater retention of $\mathrm{AlPcS}_{2 \mathrm{a}}$ in the tumour than in the surrounding tissue and the fluorescence microscopy showed that the drug is localised in tumour cells. This would appear to be the best time interval between drug administration and light delivery. These results correlate well with other reports and indicate that the structural properties of the sarcoma tissue do not spoil the possibility of using PCI as a new treatment modality (Peng and Moan, 1995; Selbo et al, 2001). The results are also in accordance with previous studies, which indicated that $\mathrm{AlPcS}_{2 \mathrm{a}}$ is located in the cells of an experimental malignant melanoma rather than in the interstitium (Peng et al, 1991a,b), and that the compound has a high tumour to tissue ratio (Chan et al, 1990).

Our results showed an increased survival time in tumourbearing animals using the combination of the photoactivation of $\mathrm{AlPcS}_{2 \mathrm{a}}$ and gelonin (PCI) compared with PDT alone (light and $\mathrm{AlPcS}_{2 \mathrm{a}}$ ) or gelonin alone. The $50 \%$ complete response rate observed after PCI correlated with necrosis reaching a depth of $7 \mathrm{~mm}$ and covering a mean of more than $97 \%$ of the cut surface of tumours examined 4 days after light delivery. After PDT, the depth of necrosis was no more than $3-4 \mathrm{~mm}$. This may indicate that tumour eradication is related to a threshold number of tumour cells surviving the treatment, and that this threshold may be around $2.5 \%$. In this study, the gelonin was given by direct i.t. injection, so it is difficult to know exactly where it was located, but it may also be possible to administer it systemically, when one could be more confident that it reached all the cells in the target area. Our findings also provide evidence that PCI using gelonin effectively reduces the light fluence needed to obtain a cytotoxic effect inside tumours compared with PDT alone (Berg et al, 1999; Selbo et al, 2001). The fluence rate of $670 \mathrm{~nm}$ light is reduced by $50 \%$ at a depth of $3 \mathrm{~mm}$ (Moan et al, 1998).

This study was undertaken to investigate the possibility of using PCI in the treatment of sarcoma patients before, during or after surgery, particularly to reduce the incidence of local recurrence. At present, $50 \%$ of patients die within 5 years due to local relapse or metastases (Dirix and Van Oosterom, 1999). Chemotherapy and radiation therapy often do not give satisfactory results and have the disadvantages of troublesome side effects. Photochemical internalisation has few side effects since the treatment effect is localised to the illuminated area apart from skin photosensitivity due to the photosensistiser, which is reasonably easy to control. New developments in molecular biology have led to experimental therapeutic approaches designed specifically to target changes in malignant cells (Hunt and Feig, 1999). Previously we reported the 


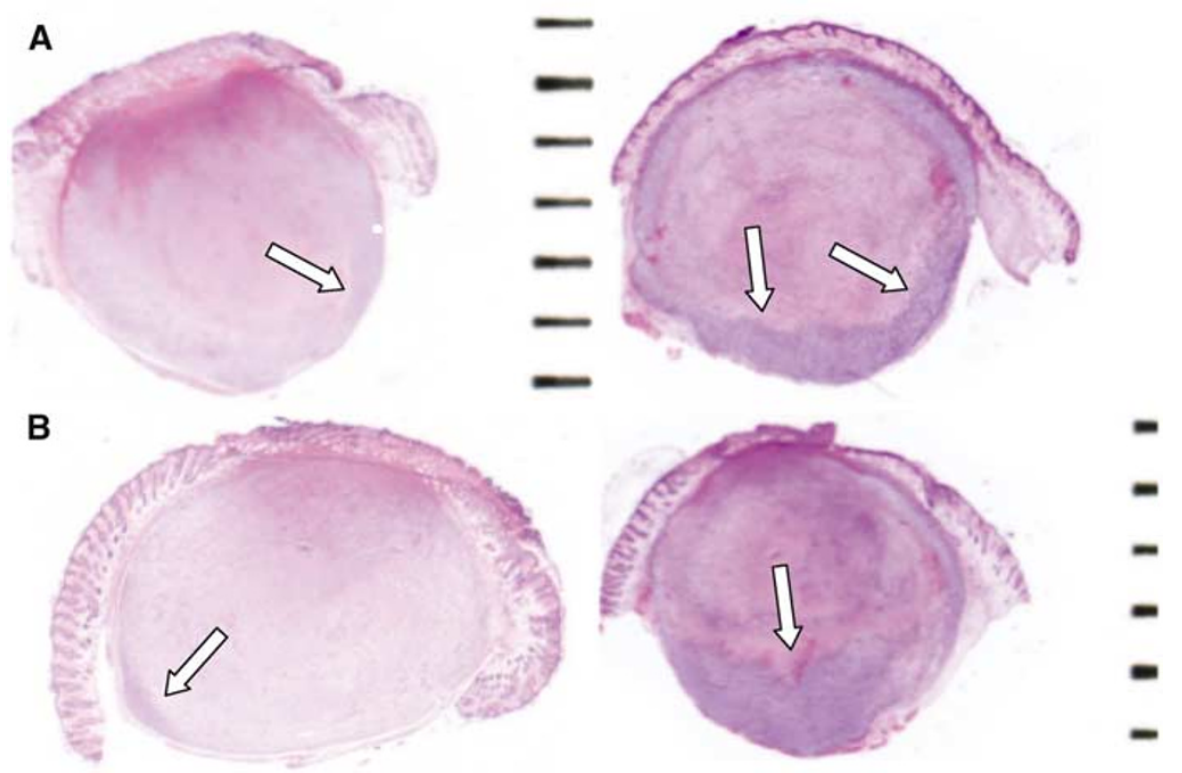

Figure 6 Photomicrographs of tumours 4 days after treatment. Areas of complete necrosis were clearly demarcated from adjacent viable tissue (arrows). (A) Tumour treated with $\mathrm{PCl}$. (B) tumour treated with PDT.

possibility of using PCI for the targeted delivery of macromolecules to cancer cells (Selbo et al, 2000; Prasmickaite et al, 2002; Kloeckner et al, 2004). The combination of light-directed therapy and molecular targeting which is possible using PCI could become a powerful adjuvant treatment modality, which could meet the needs of many patients with localised tumours that are difficult to eradicate with current techniques.

\section{REFERENCES}

Berg K, Kristian Selbo P, Prasmickaite L, Tjelle TE, Sandvig K, Moan J, Gaudernack G, Fodstad O, Kjolsrud S, Anholt H, Rodal GH, Rodal SK, Hogset A (1999) Photochemical internalization: a novel technology for delivery of macromolecules into cytosol. Cancer Res 59: 1180-1183

Chan WS, Marshall JF, Svensen R, Bedwell J, Hart IR (1990) Effect of sulfonation on the cell and tissue distribution of the photosensitizer aluminum phthalocyanine. Cancer Res 50: 4533-4538

Cramers P, Ruevekamp M, Oppelaar H, Dalesio O, Baas P, Stewart FA (2003) Foscan uptake and tissue distribution in relation to photodynamic efficacy. Br J Cancer 88: 283-290

Dietze A, Bonsted A, Hogset A, Berg K (2003) Photochemical internalization enhances the cytotoxic effect of the protein toxin gelonin and transgene expression in sarcoma cells. Photochem Photobiol 78: 283-289

Dirix LY, Van Oosterom AT (1999) Soft tissue sarcoma in adults. Curr Opin Oncol 11: $285-295$

Dolmans DE, Fukumura D, Jain RK (2003) Photodynamic therapy for cancer. Nat Rev Cancer 3: 380-387

Dougherty TJ (2002) An update on photodynamic therapy applications. J Clin Laser Med Surg 20: 3-7

Dougherty TJ, Gomer CJ, Henderson BW, Jori G, Kessel D, Korbelik M, Moan J, Peng Q (1998) Photodynamic therapy. J Natl Cancer Inst 90: $889-905$

Hunt KK, Feig BW (1999) Preclinical experimental therapeutic approaches in soft tissue sarcoma. Semin Surg Oncol 17: 78-82

Jones HJ, Vernon DI, Brown SB (2003) Photodynamic therapy effect of mTHPC (Foscan) in vivo: correlation with pharmacokinetics. Br J Cancer 89: $398-404$

Kloeckner J, Prasmickaite L, Hogset A, Berg K, Wagner E (2004) Photochemically enhanced gene delivery of EGF receptor-targeted DNA polyplexes. J Drug Target 12: 205-213

\section{ACKNOWLEDGEMENTS}

We thank Hanne Mali Thesen Møllegaard, Marie-Therese Roppestad Strand and Marita Martinsen for skilful technical assistance. We also thank The Norwegian Cancer Society and The Research Foundation at The Norwegian Radium Hospital, Oslo for financial support.
Lieberman MW, Lebovitz RM (1990) Neoplasia. In Anderson's Pathology Damjanov I, Linder I (eds) pp 513 - 547. Mosby-Year Book, Inc.: St Louis, Missouri

Moan J, Berg K, Iani V (1998) Action spectra of dyes relevant for photodynamic therapy. In Photodynamic tumor therapy Moser JG (ed) pp 169 - 181. London: Harwood

Peng Q, Moan J (1995) Correlation of distribution of sulphonated aluminium phthalocyanines with their photodynamic effect in tumour and skin of mice bearing $\mathrm{CaD} 2$ mammary carcinoma. $\mathrm{Br} \mathrm{J}$ Cancer 72: $565-574$

Peng Q, Moan J, Farrants G, Danielsen HE, Rimington C (1991a) Localization of potent photosensitizers in human tumor LOX by means of laser scanning microscopy. Cancer Lett 58: 17-27

Peng Q, Moan J, Kongshaug M, Evensen JF, Anholt H, Rimington C (1991b) Sensitizer for photodynamic therapy of cancer: a comparison of the tissue distribution of Photofrin II and aluminum phthalocyanine tetrasulfonate in nude mice bearing a human malignant tumor. Int $J$ Cancer 48: 258-264

Prasmickaite L, Hogset A, Berg K (2002) Photochemical transfection. Light-induced, site-directed gene delivery. Methods Mol Med 69: $123-135$

Selbo PK, Hogset A, Prasmickaite L, Berg K (2002) Photochemical internalisation: a novel drug delivery system. Tumour Biol 23: $103-112$

Selbo PK, Sivam G, Fodstad O, Sandvig K, Berg K (2000) Photochemical internalisation increases the cytotoxic effect of the immunotoxin MOC31-gelonin. Int J Cancer 87: 853-859

Selbo PK, Sivam G, Fodstad O, Sandvig K, Berg K (2001) In vivo documentation of photochemical internalization, a novel approach to site specific cancer therapy. Int J Cancer 92: 761-766 